\title{
A modified ionic liquid clay to remove heavy metals from water: investigating its catalytic activity
}

\author{
S. Kakaei ${ }^{1}$ - E. S. Khameneh ${ }^{2} \cdot$ M. H. Hosseini ${ }^{2} \cdot$ M. M. Moharreri $^{3}$
}

Received: 11 June 2019 / Revised: 31 July 2019 / Accepted: 27 August 2019 / Published online: 12 September 2019

(c) The Author(s) 2019

\begin{abstract}
The new clay modified with triazole and triazolium ligands was prepared in this research. These materials were applied as abundant and eco-friendly adsorbents for removal of heavy metal ions such as $\mathrm{Pb}$ (II), $\mathrm{Co}$ (II) and $\mathrm{Zn}$ (II) ions. The adsorption efficiency of these materials was calculated by relevant equations such as Langmuir and Freundlich as well as kinetic studies with pseudo-first-order and pseudo-second-order models. These adsorbents proved to be very active on heavy metal ion adsorption. The characterization of these new materials was carried out by various techniques such as X-ray diffraction, thermogravimetric analysis, scanning electron microscope (SEM), X-ray photoelectron spectroscopy and energy-dispersive $\mathrm{X}$-ray spectroscopy as well as SEM-map analysis. Eventually, the catalytic activity of the adsorbents which treated with heavy metal ion solutions was studied in the reduction of nitroarenes to its corresponding amines. The prepared adsorbent-catalyst materials indicated efficient catalytic activity in the reduction of nitroarenes to amines in ambient conditions.
\end{abstract}

Editorial responsibility: Fatih Şen.

Electronic supplementary material The online version of this article (https://doi.org/10.1007/s13762-019-02527-9) contains supplementary material, which is available to authorized users.

S. Kakaei

Skakaei@aeoi.org.ir

1 Radiation Application Research School, Nuclear Science and Technology Research Institute, P. O. Box 11365-3486, Tehran, Iran

2 Materials and Nuclear Fuel Research School, Nuclear Science and Technology Research Institute, P. O. Box 11365-3486, Tehran, Iran

3 Polymer Engineering Group, Faculty of Technology and Engineering, Golestan University, Gorgan, Iran 


\section{Graphic abstract}

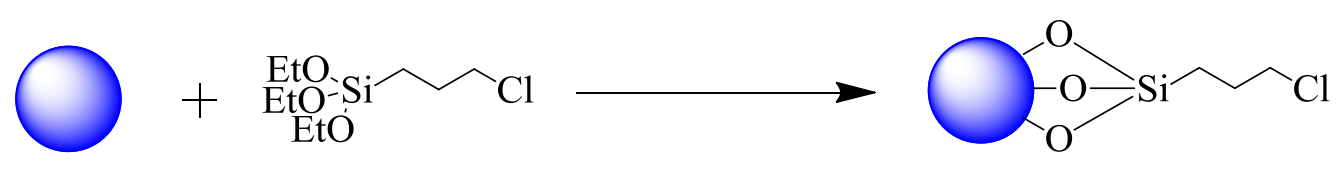

Clinochlore
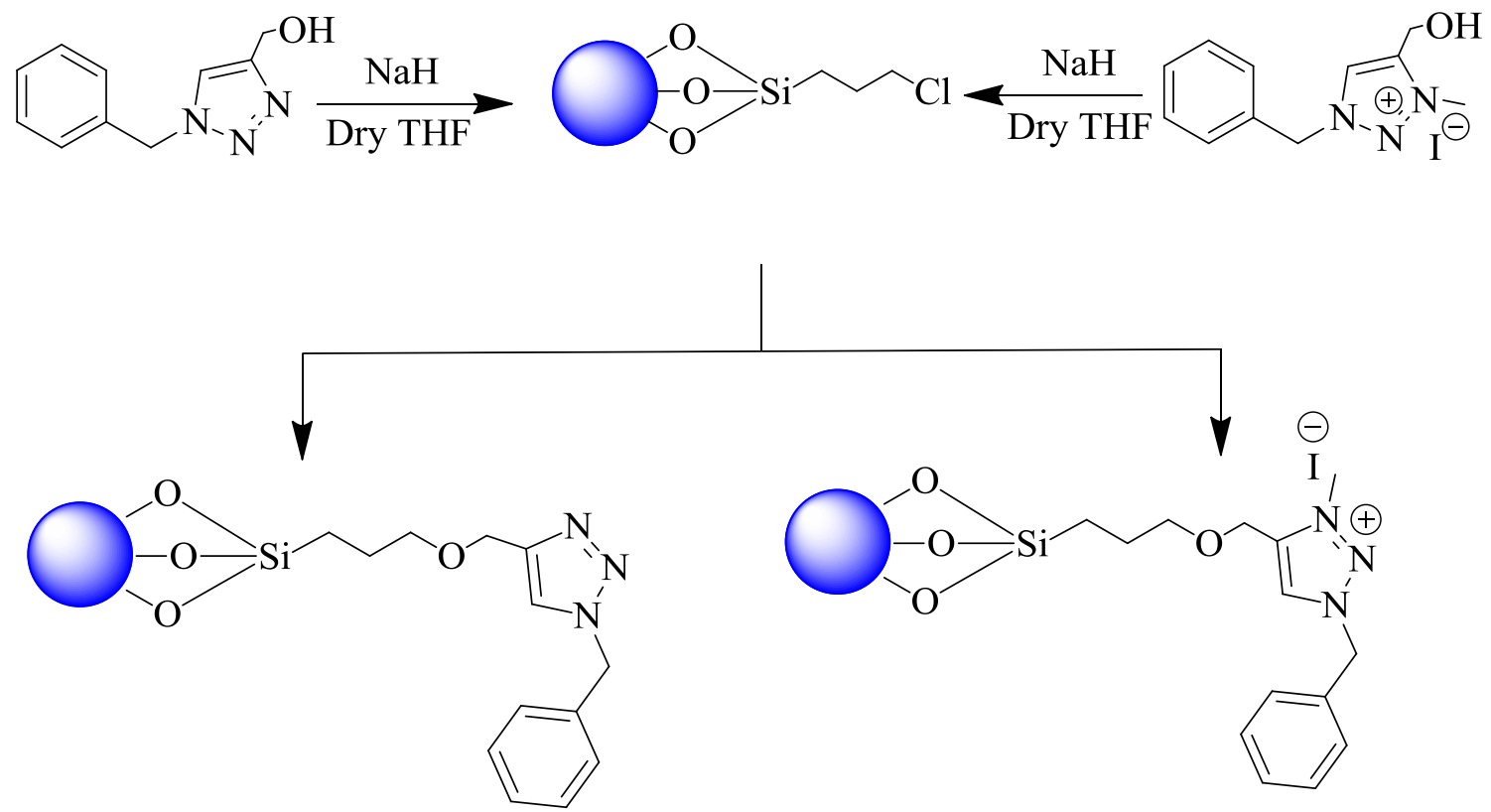

Keywords Ionic liquid · Triazole $\cdot$ Triazolium $\cdot$ Clay $\cdot$ Remove heavy metal $\cdot$ Catalytic activity

\section{Introduction}

Heavy metals toxicities are one of the most dangerous environmental contaminants which have a relatively high density compared to water (Häni 1990; Ngah and Hanafiah 2008; Fu and Wang 2011). The contamination of water and soil recourses by heavy metals is a serious worldwide problem, and it is challenging to eliminate their long-term effects (Agudosi et al. 2018a, b). The removals of these contaminants metals are crucial because they are persistent, bioaccumulative, and able to disrupt the metabolic functions and vital organs in livelihoods. Another toxic and hazardous category of organic compounds are nitroarenes, which are the common environmental contaminants and considered as major industrial activities, mining and coal combustion (Lin 1987; Tokiwa et al. 1986; Zwirner-Baier and Neumann 1999). Reduction of the nitroarenes is undoubtedly the most important way to decrease the possibility of environmental degradation by aromatic nitro compounds (Riefler and Smets 2000; Sabbioni and Jones 2002). Extensive research has been carried out to introduce materials which can remove and alleviate heavy metal ions from the wastewaters. Some of the recent important methods used for the removal of heavy metal ions are chemical precipitation (Charerntanyarak 1999), membrane filtration (Bessbousse et al. 2008), ion exchange (Dąbrowski et al. 2004), electrolytic methods (Nojiri et al. 1980), and solvent extraction (Yun et al. 1993). However, these methods have several disadvantages such as high reagent requirement, unpredictable metal ion removal, generation of toxic sludge, etc. Among the different techniques, the adsorption process is considered as the best one because it is straightforward, economically very significant, practical and versatile, which has become the most preferred method for removal of toxic contaminants from wastewater. Such materials are zeolites, biosorbents, activated carbon, fly ash, mesoporous and clays which have gained more attention than the other adsorbents due to the high surface area as well as being eco-friendly (Zhu et al. 2012; Padilla-Ortega et al. 2013).

Clay is a naturally occurring compound of aluminum silicate $\left((\mathrm{AlO})_{2} \mathrm{SiO}_{3}\right)$ composed of fine-grained minerals which have gained much attention during the recent 
decades (Alvarez-Ayuso and Garćia-Sánchez 2003; Uddin 2017). They are defined as soils with particles smaller than $2 \mu \mathrm{m}$ having a layer structure (Velde 1992; Chenu and Plante 2006). Small size and layer structure provide them with a high surface area; hence, it is capable of heavy metal adsorption within its layers (Velde 1992; Bhattacharyya and Gupta 2008). Among different kinds of clays, clinochlore is an important one which belongs to the chlorite group (Welch and Marshall 2001; Kleppe et al. 2003; Gopal et al. 2004). The chemical formula of clinochlore is $\left(\mathrm{Mg}_{5} \mathrm{Al}\right)\left(\mathrm{AlSi}_{3}\right) \mathrm{O}_{10}(\mathrm{OH})_{8}$, and it crystallizes in monoclinic (Welch and Marshall 2001; Kleppe et al. 2003; Gopal et al. 2004). Due to strong interactions between the elements such as nitrogen, sulfur and phosphor with few heavy metals like $\mathrm{Cu}, \mathrm{Cd}, \mathrm{Pb}, \mathrm{Zn}, \mathrm{Ni}$, Co and also in order to increase adsorption efficacy, the clays are modified with sorts of ligand (Celis et al. 2000; Esalah and Husein 2008; Jlassi et al. 2018). Potentially, clays can physisorbed the metals in their structures, but in this case, the adsorption capacity has a limited value which could be increased by modification of clay surface (Altın et al. 1998; Lin and Juang 2002; Bhattacharyya and Gupta 2008).

In this study, we modified the raw clinochlore with triazole and triazolium ligands and its application for adsorption of heavy metal ions such as $\mathrm{Co}(\mathrm{II}), \mathrm{Pb}$ (II) and $\mathrm{Zn}$ (II) from industrial wastewater is presented. Moreover, the catalytic activities of the modified clinochlore which are treated with heavy metal ions were proved in the reduction of nitroarenes to amines.

\section{Materials and methods}

\section{Experimental}

All materials were purchased from Sigma-Aldrich, Acros and Merck Millipore. Reactions were monitored by thinlayer chromatography (TLC) using Merck silica gel 60F254 glass plate with $0.25 \mathrm{~mm}$ thickness. Clinochlore was purchased from Daneshmand chemical trading co (Iran). Column chromatography was carried out on silica gel 60 Merck (230-240 mesh) in a 2-cm-diameter column. ${ }^{1} \mathrm{H}$ NMR and ${ }^{13} \mathrm{C}$ NMR spectra were recorded at $400 \mathrm{MHz}$ and $100 \mathrm{MHz}$, respectively, on a Bruker Avance HD. Chemical shifts are given on the $\delta$-scale in ppm, and residual solvent peaks were used as internal standards. X-ray diffraction (XRD) patterns were recorded using Philips X'Pert Pro instrument. The SEM images were captured with JEOL JSM 840. XPS analyses were performed using a K-Alpha spectrometer. Thermogravimetric analysis was conducted from room temperature to $800{ }^{\circ} \mathrm{C}$ in an oxygen flow using a NETZSCH STA 409 $\mathrm{PC} / \mathrm{PG}$ instrument.
Synthesis of (1-benzyl-1H-1,2,3-triazol-4-yl) methanol (Tzl-OH)

In a 10 -mL flask, sodium azide ( $1.5 \mathrm{mmol}, 97.5 \mathrm{mg})$, benzyl bromide $(1 \mathrm{mmol}, 0.11 \mathrm{~mL})$, methanol $(2 \mathrm{~mL})$ and deionized water $(0.1 \mathrm{~mL})$ were added and stirred for $30 \mathrm{~min}$ at room temperature. Then propargyl alcohol $(3 \mathrm{mmol}, 0.17 \mathrm{~mL})$ and copper iodide $(0.1 \mathrm{mmol}, 19 \mathrm{mg})$ were added to the mixture, and the reaction was stirred at room temperature. After $72 \mathrm{~h}$, the reaction mixture was diluted with deionized water and extracted with ethyl acetate $(3 \times 5 \mathrm{~mL})$. The combined organic layers were dried over $\mathrm{Na}_{2} \mathrm{SO}_{4}$. Afterward, the resulting solution was concentrated with a rotary evaporator and further purification was done by column chromatography. The product was achieved in $90 \%$ isolated yield. In order to dry the resultant product, it was placed in $60{ }^{\circ} \mathrm{C}$ oven for $24 \mathrm{~h}$.

\section{Synthesis of 1-benzyl-4-(hydroxymethyl)-3-methyl-1H-1,2,3 -triazolium (IL-TzI-OH)}

In a 10 -mL flask, dry acetonitrile $(5 \mathrm{~mL})$ was added to (1-benzyl-1H-1,2,3-triazol-4-yl)methanol (2 mmol, $378 \mathrm{mg}$ ) and stirred for $10 \mathrm{~min}$. Then methyl iodide $(10 \mathrm{mmol}$, $0.623 \mathrm{~mL}$ ) was added to the mixture slowly, and the reaction was stirred for $24 \mathrm{~h}$ under reflux condition. After the reaction time, the mixture was washed with ethyl acetate $(3 \times 5 \mathrm{~mL})$ and the resulting sticky oil was placed in the rotary evaporator to remove the remaining amount of methyl iodide. The product was obtained in $96 \%$ isolated yield. The resulting product was placed in an oven of $50{ }^{\circ} \mathrm{C}$ under vacuum condition for overnight.

\section{Preparation of Cl@clinochlore (Cl@Clin)}

In a $50-\mathrm{mL}$ flask, dry toluene $(10 \mathrm{~mL})$ was added to clinochlore (1 g), and it was sonicated for $15 \mathrm{~min}$. Next (3-chloropropyl)triethoxysilane ( $5 \mathrm{mmol}, 1.2 \mathrm{~mL}$ ) was added to the mixture slowly, and it was reflux for $24 \mathrm{~h}$ under argon atmosphere. After $24 \mathrm{~h}$, the whole reaction mixture was poured to a $15-\mathrm{mL}$ falcon and centrifuged at $4000 \mathrm{rpm}$ for $15 \mathrm{~min}$. Then, the supernatant was decanted, and the remaining solid was washed with deionized water $(10 \mathrm{~mL})$ and acetone $(10 \mathrm{~mL})$. Next, the mixture was centrifuged again and the final sediment was placed in an oven of $60^{\circ} \mathrm{C}$ for $24 \mathrm{~h}$.

\section{Preparation of TzI-OH@Clin and IL-TzI-OH@Clin}

In a $25-\mathrm{mL}$ flask, dry THF $(10 \mathrm{~mL})$ was added to Tzl-OH $(1 \mathrm{mmol}, 189 \mathrm{mg})$ or IL-Tzl-OH (1 mmol, $331 \mathrm{mg})$ and stirred for $15 \mathrm{~min}$ at room temperature under argon atmosphere. Then, sodium hydride $(\mathrm{NaH})(2 \mathrm{mmol}, 48 \mathrm{mg})$ was added to the mixture under argon atmosphere. The mixture 
was stirred at room temperature for $1 \mathrm{~h} . \mathrm{Next}, \mathrm{Cl} @ \mathrm{Clin}$ $(0.5 \mathrm{~g})$ was added to the mixture, and the reaction was refluxed under argon atmosphere for $24 \mathrm{~h}$. Afterward, the reaction was allowed to reach the room temperature, and the residue solid was separated by centrifugation $(15 \mathrm{~min}$ at $3500 \mathrm{rpm})$. The resulting sediment was washed with deionized water $(10 \mathrm{~mL})$ and acetone $(10 \mathrm{~mL})$, respectively. The obtained material (Tzl-OH@Clin) or (IL-Tzl-OH@Clin) was placed in an oven of $60^{\circ} \mathrm{C}$ for $24 \mathrm{~h}$.

\section{Adsorption experiments}

In order to perform adsorption experiments, the adsorbent $(5 \mathrm{mg})$ was added to the aqueous solution $(20 \mathrm{~mL}, 20 \mathrm{mg} / \mathrm{L})$ of $\mathrm{Co}(\mathrm{II}), \mathrm{Zn}$ (II) and $\mathrm{Pb}$ (II). The mixture was stirred for $3 \mathrm{~h}$ to reach equilibrium adsorption capacity. Then, the mixture was centrifuged at $2000 \mathrm{rpm}$ for $15 \mathrm{~min}$, and atomic adsorption analysis (AAS) of the resulting supernatant determined the concentration of heavy metal ions after treatment. All the adsorption experiments were carried out at room temperature $\left(25^{\circ} \mathrm{C}\right)$.

The equilibrium adsorption capacity and equilibrium adsorption capacity at the time $(t)$ were calculated by the following equations.

$q_{\mathrm{e}}=\frac{\left(C_{0}-C_{\mathrm{e}}\right) V}{m}$

$q_{t}=\frac{\left(C_{0}-C_{t}\right) V}{m}$

where $C_{0}$ is initial heavy metal ion concentration $(\mathrm{mg} / \mathrm{L})$, $C_{\mathrm{e}}$ is the concentration of heavy metal ion after equilibrium $(\mathrm{mg} / \mathrm{L}), C_{t}$ is the concentration of heavy metal ion at time $t$ $(\mathrm{mg} / \mathrm{L}), V$ is the solution volume $(\mathrm{L})$, and $m$ is the mass of adsorbent $(\mathrm{g})$.

\section{Effect of initial heavy metals ion concentrations on equilib- rium adsorption capacities}

In order to investigate the effect of initial heavy metal ion concentration on adsorption capacity, the same process as the above part was done except the initial heavy metal ion concentrations were changed to $10-80 \mathrm{mg} / \mathrm{L}$ for $\mathrm{Pb}(\mathrm{II})$, $\mathrm{Zn}(\mathrm{II})$ and $\mathrm{Co}(\mathrm{II})$. In order to prevent heavy metal ion precipitation by $\mathrm{OH}^{-}$and higher efficiency of adsorbents, the $\mathrm{pH}$ values were set to 5 for this experiment.

\section{Effect of pH on the equilibrium adsorption capacity}

To study the equilibrium adsorption capacity changes in different $\mathrm{pH}$ values, the experiments were carried out on the $\mathrm{pH}$ range of $2-8$. The $\mathrm{pH}$ value was fixed to 2 by using the buffer solution of $\mathrm{KCl} / \mathrm{HCl}$, sodium acetate/acetic acid for pH range of 3-6 and HEPES-Na (4-(2-hydroxyethyl)-piperazine-1-ethanesulfonic acid, sodium salt) for $\mathrm{pH}$ range of 7-8.

\section{Kinetic study}

To study kinetic behavior of adsorbent, the equilibrium adsorption capacities of adsorbents $(5 \mathrm{mg}$ ) in the treatment with solutions $(20 \mathrm{~mL}, 20 \mathrm{mg} / \mathrm{L}$ ) of $\mathrm{Pb}$ (II), $\mathrm{Zn}$ (II) and $\mathrm{Co}$ (II) were determined in the time intervals of $0-180 \mathrm{~min}$ and the $\mathrm{pH}$ value was set to 5 .

\section{Procedure for adsorption of heavy metal ions in industrial wastewater}

In order to study removal efficacy in industrial wastewaters, first, the solution $(20 \mathrm{mg} / \mathrm{L}, 20 \mathrm{~mL})$ of the $\mathrm{Pb}$ (II), $\mathrm{Co}$ (II) and $\mathrm{Zn}$ (II) was made and treated with Tzl-OH@Clin(10, 50 and $100 \mathrm{mg}$ ) for $3 \mathrm{~h}$. Then, the whole mixture was centrifuged, and the concentrations of heavy metal ions were determined by atomic absorption of the supernatants.

\section{Determination of Co(II) concentration on the Tzl-OH@Clin structure by AAS}

In order to determine the concentration of adsorbed Co(II) in the absorbent structure, the adsorbent treated with $\mathrm{Co}(\mathrm{II})$ solution $(20 \mathrm{mg})$ was dissolved in aqua regia $(5 \mathrm{~mL})$ and stirred for $12 \mathrm{~h}$. Then, the mixture was poured to the $15-\mathrm{mL}$ falcon, and it was centrifuged at $3000 \mathrm{rpm}$ for $10 \mathrm{~min}$. Next, the supernatant was decanted to the volumetric flask $(25 \mathrm{~mL})$ and reached the total volume to $25 \mathrm{~mL}$ via deionized water. Afterward, the concentration of the metal was gained by the AAS of the resulting solution.

\section{Procedure for reduction of nitroarenes}

To perform nitro reduction reaction, in a 10-mL flask, TzlOH@Clin treated with Co(II) solution (15 mg, $1.60 \mathrm{~mol} \%)$ was added to the sodium borohydride solution $[2.7 \mathrm{mM}$ in $1.5 \mathrm{~mL}$ mixture of deionized water and THF (9:1)]. Then the nitroarene $(1 \mathrm{mmol})$ was added to the mixture slowly and stirred for different time intervals. The completion of the reaction was monitored by TLC. After the reaction was completed, the mixture was diluted with deionized water $(4 \mathrm{~mL})$ and it was extracted with ethyl acetate $(3 \times 2 \mathrm{~mL})$. Next, the combined organic layer was treated with sodium sulfate and it was filtered and the resulting organic layer was concentrated with a rotary evaporator. The yield was obtained by gas chromatography (GC), and the further purification was done by column chromatography. 


\section{Results and discussion}

Synthesis of (1-benzyl-1H-1,2,3-triazol-4-yl)methanol (Tzl$\mathrm{OH})$ and 1-benzyl-4-(hydroxymethyl)-3-methyl-1H-1,2,3triazolium (IL-Tzl-OH) was proceeded by the initial synthesis of benzyl azide, and its reaction was shown with propargyl alcohol in the presence of copper iodide as the catalyst at room temperature. The corresponding 1,2,3-triazole $(\mathrm{Tzl}-\mathrm{OH})$ product was treated with methyl iodide under reflux condition to obtain 1,2,3-triazolium (IL-Tzl-OH) product. Further, to modify raw clinochlore with triazole and triazolium ligand, firstly the chlorinated clinochlore (Cl@ Clin) was made by adding 3-chloropropyltriethoxysilane to the fresh clinochlore and then the grafting process for both Tzl-OH and IL-Tzl-OH to Cl@Clin was done by treating ligands with sodium hydride in THF and adding $\mathrm{Cl} @ \mathrm{Clin}$ at the end. Finally, the clinochlore modified with triazole (TzlOH@Clin) and triazolium (IL-Tzl-OH@Clin)was obtained (Scheme 1).

The ${ }^{1} \mathrm{H}$ and ${ }^{13} \mathrm{C}$ NMR spectra of both Tzl-OH and ILTzl-OH were investigated, and it shows synthesis processes of the corresponding products were successful (Figs. 1 and 2 ESI).

The thermogravimetric analysis (TGA) of Cl@Clin, TzlOH@Clin and IL-Tzl-OH@Clin showed a weight loss at $120{ }^{\circ} \mathrm{C}$, which is due to the presence of some water molecules in the structures. Also, related to the Cl@Clin, two increases on the weight loss were observed in $200{ }^{\circ} \mathrm{C}$ for Tzl-OH@Clin and IL-Tzl-OH@Clin, which is according to the additional of organic groups contained in grafted ligands to the $\mathrm{Cl} @ \mathrm{Clin}$. Overall weight loss of IL-Tzl-OH@Clin
Scheme 1 The schematic routes for the preparation of Tzl-OH@ Clin and IL-Tzl-OH@Clin
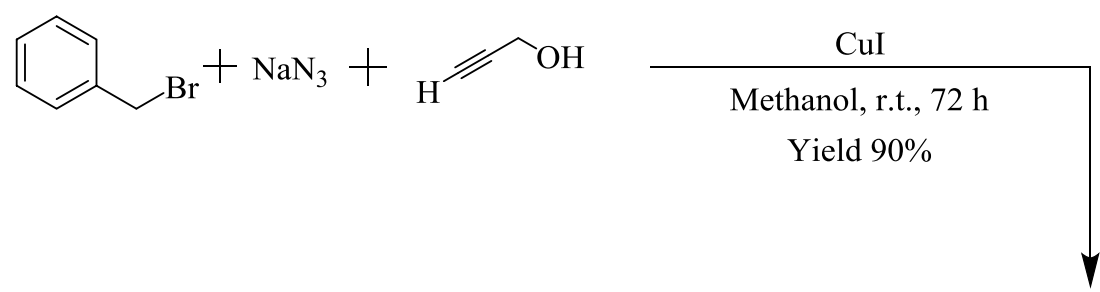<smiles>OCc1cn(Cc2ccccc2)nn1</smiles>

(2)

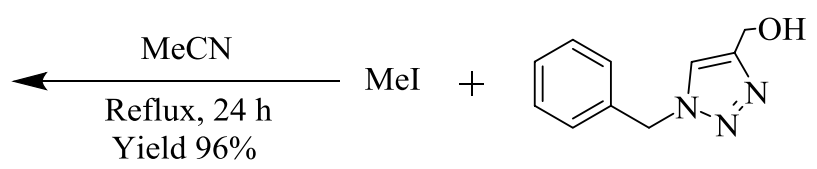

(1)

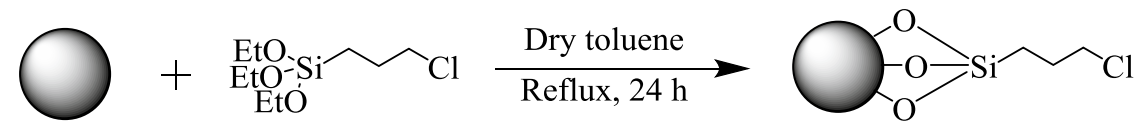

Clinochlore

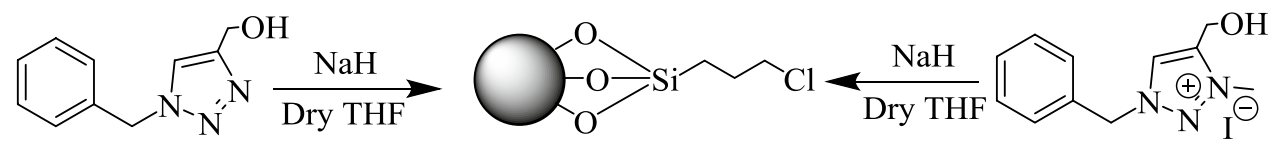

(1)

(3)

(2)

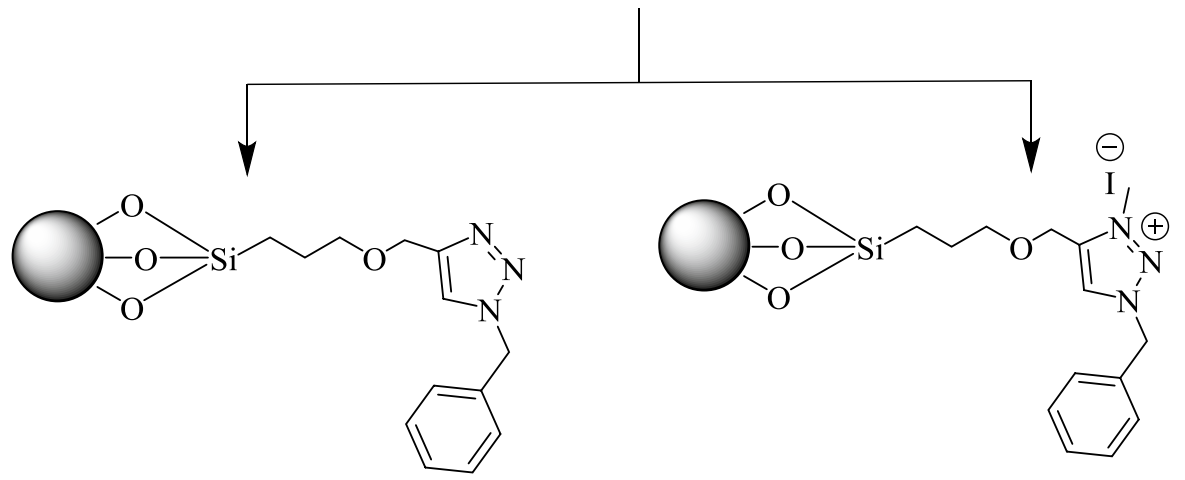

(4)

(5) 


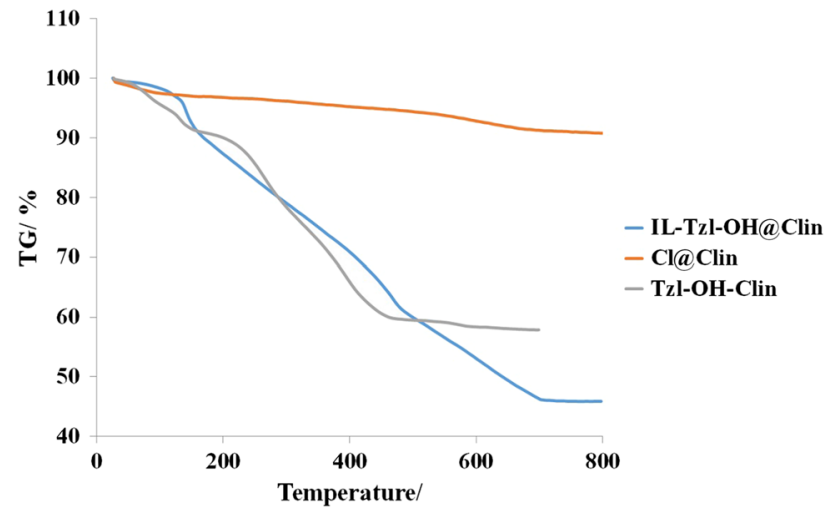

Fig. 1 TG analyses of Cl@Clin, Tzl-OH@Clin and IL-Tzl-OH@Clin

was about 54.12\% and for Tzl-OH@Clin was about 42.13\%, which is smaller than IL-Tzl-OH@Clin. This may relate to addition of methyl and some heavy elements such as iodine $\left(\mathrm{I}^{-}\right)$to the triazole structure (Fig. 1).

The X-ray photoelectron spectroscopy (XPS) study of the Tzl-OH@Clin in the nitrogen region showed two peaks at the binding energies of 400.18 and $401.88 \mathrm{eV}$ which are related to the triazole nitrogen (Fig. 2a) (Fortgang et al. 2016). The XPS spectra of IL-Tzl-OH@Clin at nitrogen region showed a single peak at the binding energy of $402 \mathrm{eV}$ which is related to triazolium nitrogens (Fig. 2b) (Obadia et al. 2015).

In order to investigate the structure of clinochlore, the SEM images at different magnifications were taken (Fig. 3).

An X-ray powder diffraction (XRD) spectrum of clinochlore was also examined (Fig. 4), and the XRD pattern was similar to previous literature (Hemanthkumar et al. 2009).

\section{Heavy metal ion adsorption}

In order to study the adsorption ability of clinochlore, TzlOH@Clin and IL-Tzl-OH@Clin, the solution of Zn(II), $\mathrm{Co}(\mathrm{II})$ and $\mathrm{Pb}$ (II) $(20 \mathrm{mg} / \mathrm{L})$ was treated with the specified amount of adsorbents $(5 \mathrm{mg}$ ) at room temperature. Equilibrium adsorption capacities $\left(q_{\mathrm{e}}\right)$ were achieved after 3 -h stirring of the adsorbents with metal ion solutions. In order to compare the adsorption efficacy of three adsorbents, the

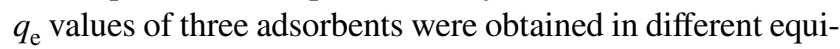
librium concentrations $\left(C_{\mathrm{e}}\right)$, and the results are shown in Fig. 5. According to the results, the $q_{\mathrm{e}}$ values for Tzl-OH@ Clin were higher than raw clinochlore and IL-Tzl-OH@Clin which shows better interactions of triazole nitrogens with heavy metal ions (Fig. 5).
Fig. 2 XPS analysis of a TzlOH@Clin and b IL-Tzl-OH@ Clin in the nitrogen region
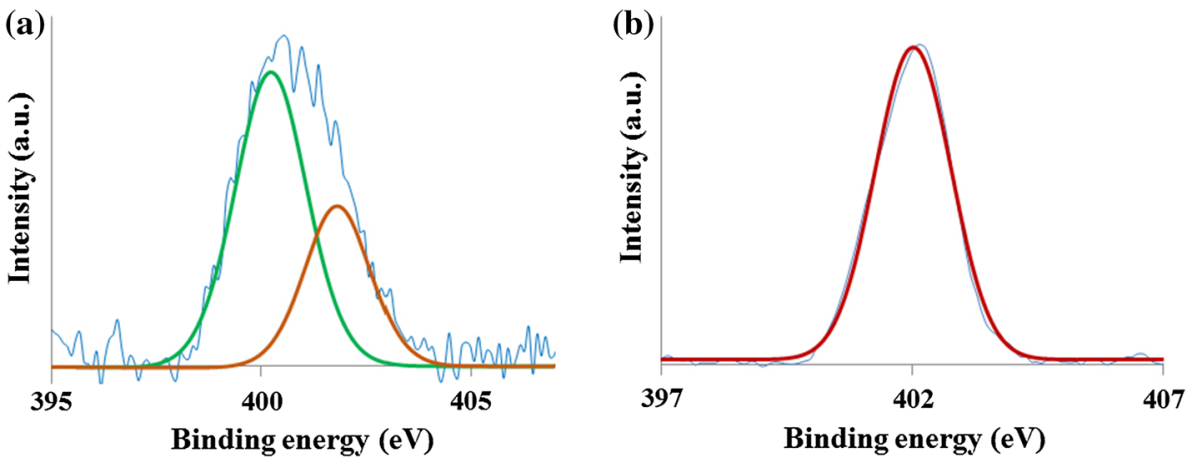
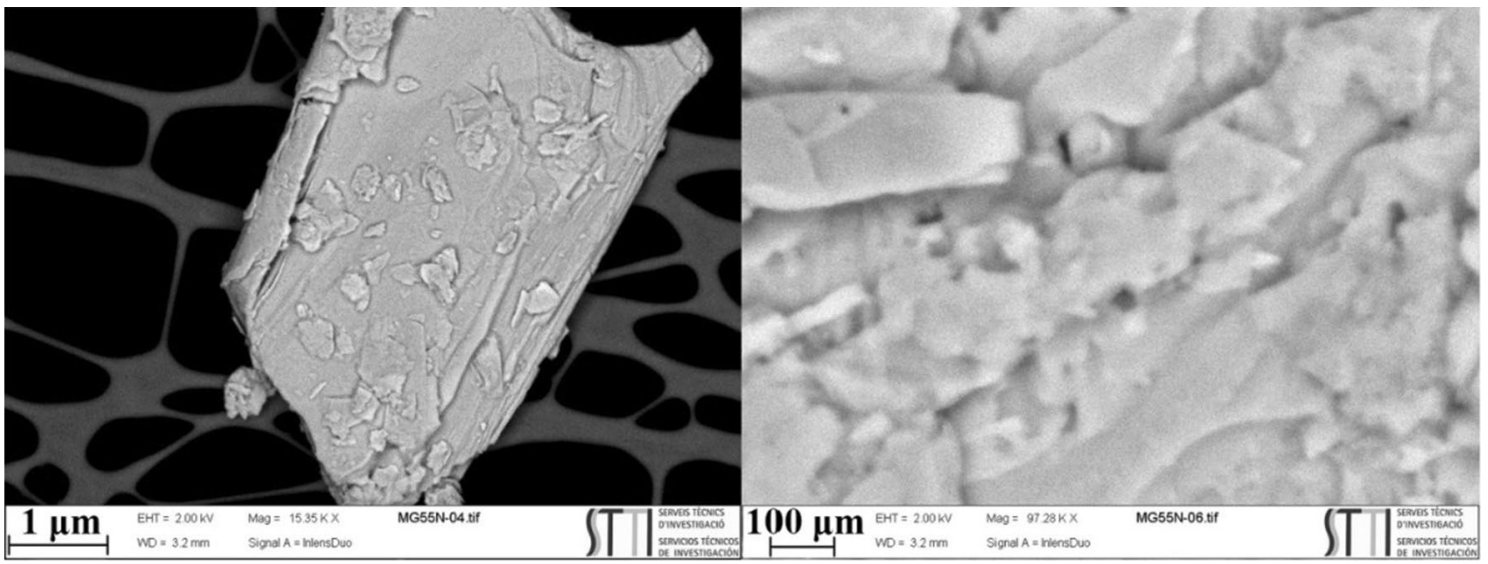

Fig. 3 SEM images of Tzl-OH@Clin at different magnifications 


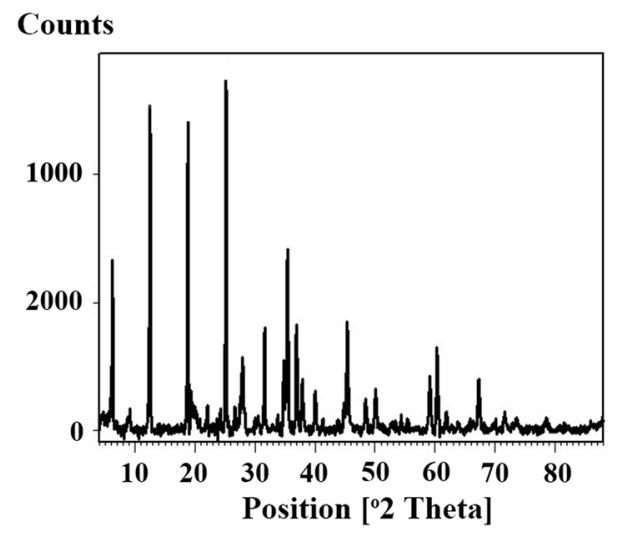

Fig. 4 XRD spectrum of clinochlore

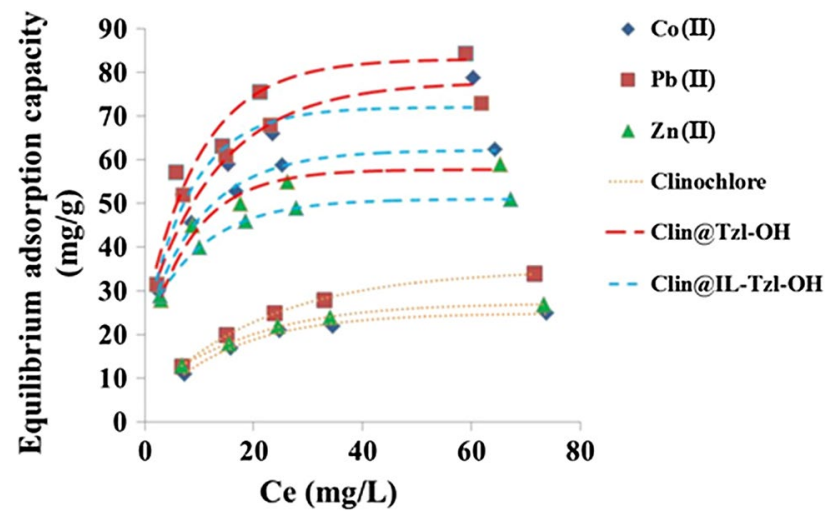

Fig. 5 Adsorption isotherms of $\mathrm{Co}(\mathrm{II}), \mathrm{Pb}$ (II) and $\mathrm{Zn}$ (II) for raw clinochlore, Tzl-OH@Clin and IL-Tzl-OH@Clin as adsorbents

At the same above conditions, the experiments were performed in a different range of $\mathrm{pH}(2-8)$. The results indicated that on the $\mathrm{pH}$ of 5 , the maximum amounts of $q_{\mathrm{e}}$ were obtained and at higher $\mathrm{pH}$, the amounts of $q_{\mathrm{e}}$ were decreased. It may be due to precipitation of metal ions with hydroxide ions $\left(\mathrm{OH}^{-}\right)$. Also, at $\mathrm{pH} 4$, the $q_{\mathrm{e}}$ values did not have significant changes. On the $\mathrm{pH}$ amounts of 3 and 2 , the $q_{\mathrm{e}}$ values decreased and it is probably caused by disturbance of $\mathrm{H}^{+}$Ions and its interaction with triazole nitrogens which may prevent metal ions from being adsorbed by Tzl-OH@Clin and ILTzl-OH@Clin. No significant changes were observed in raw clinochlore as an adsorbent with $\mathrm{pH}$ decreasing (Fig. 6).

The effect of initial heavy metal ion concentration on adsorption capacity was also examined. The adsorption behaviors were studied with Langmuir and Freundlich equations (Eqs. 3 and 4).

$\frac{C_{\mathrm{e}}}{q_{\mathrm{e}}}=\frac{1}{K_{\mathrm{L}} q_{\max }}+\frac{C_{\mathrm{e}}}{q_{\max }}$

$\log q_{\mathrm{e}}=\log K_{\mathrm{f}}+\frac{1}{n} \log C_{\mathrm{e}}$ (a)

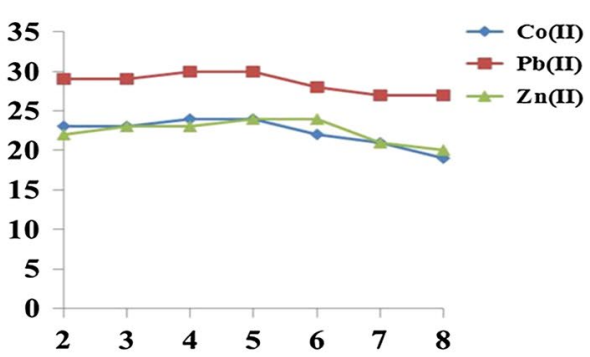

(b)

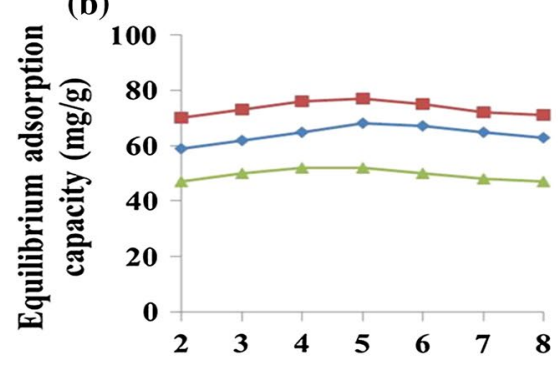

(c)

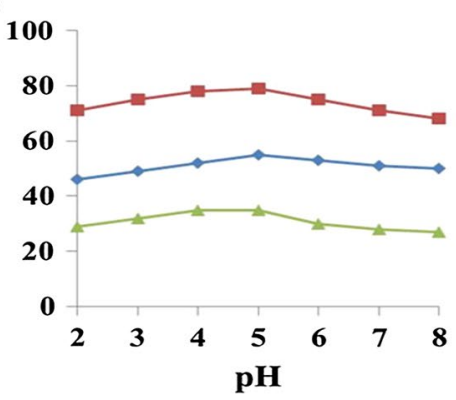

Fig. 6 Effect of $\mathrm{pH}$ on equilibrium adsorption capacity of a raw clinochlore, b Tzl-OH@Clin and c IL-Tzl-OH@Clin for adsorption of $\mathrm{Co}(\mathrm{II}), \mathrm{Pb}(\mathrm{II})$ and $\mathrm{Zn}(\mathrm{II})$

where $C_{\mathrm{e}}(\mathrm{mg} / \mathrm{L})$ is equilibrium concentration, $q_{\mathrm{e}}(\mathrm{mg} / \mathrm{g})$ is equilibrium adsorption capacity, $K_{\mathrm{L}}$ is Langmuir constant which is related to binding affinity, $q_{\max }$ is the maximum adsorption capacity $(\mathrm{mg} / \mathrm{g}), K_{\mathrm{f}}$ is the Freundlich constant which is related to the adsorption capacity, and $n$ is related to adsorption intensity.

The two isotherm models were fitted (Fig. 7), and the results are collected in Table 1.

According to results, the $q_{\max }$ values for the adsorption of Co(II) by raw clinochlore, Tzl-OH@Clin and IL-Tzl-OH@ Clin were $28.73,84.74$ and 65.78 , respectively. In addition, the adsorption capacity of Tzl-OH@Clin for adsorbing $\mathrm{Co}$ (II) was higher than that of the other two adsorbents. Also, in the case of adsorbing other metal ions, the results indicated that the best adsorption capacities were achieved by using Tzl-OH@Clin as the adsorbent. However, the adsorption capacity of IL-Tzl-OH@Clin was a bit lower than Tzl-OH@Clin, which may be due to the ionic structure of the adsorbent and establishing a weaker binding with metal ions. Also, the existence of the counter anion around 


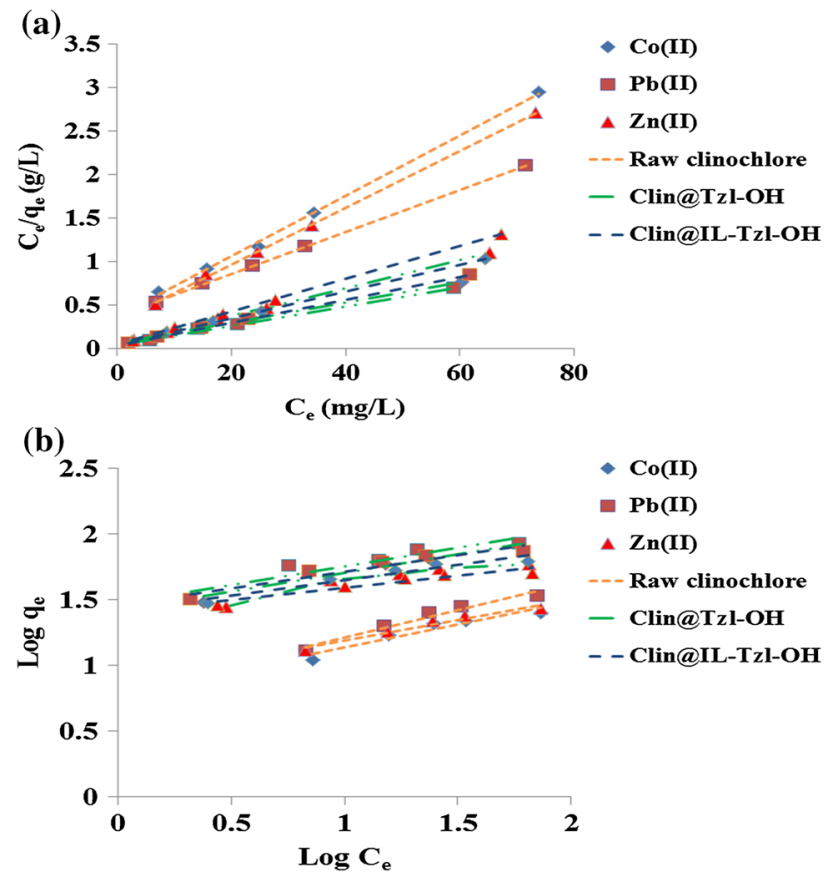

Fig. 7 Two isotherms a Langmuir and $\mathbf{b}$ Freundlich adsorption model of raw clinochlore, Tzl-OH@Clin and IL-Tzl-OH@Clin for adsorption of $\mathrm{Co}(\mathrm{II}), \mathrm{Pb}(\mathrm{II})$ and $\mathrm{Zn}$ (II)

the triazolium structure may cause some congestion for the adsorption process. The $K_{\mathrm{L}}$ values of the three adsorbent were ranged from 0.0641 to 0.3715 , all of which are positive values and show the adsorption would be desirable. The correlation coefficient $\left(R^{2}\right)$ values for the Langmuir model were from 0.9972 to 0.9998 , all of which are close to 1 , and it made the Langmuir model so favorable. The studies of Freundlich isotherms revealed the Freundlich parameters [the adsorption intensity $(n)$ and adsorption capacity $\left.\left(K_{\mathrm{f}}\right)\right]$. The $n$ values of the three adsorbents were ranged from 2.39 to 5.42. The more $n$ value is greater than 1 ( $1 / n$ closer to 0$)$, the more adsorbent shows heterogeneous behaviors (de Sá et al. 2017). In this study, the maximum $n$ values were achieved for IL-Tzl-OH@Clin as adsorbent, and in this regard, the $n$ values for adsorption of $\mathrm{Co}(\mathrm{II}), \mathrm{Pb}$ (II) and $\mathrm{Zn}$ (II) were calculated to be 4.31, 4.00 and 5.42, respectively. The $K_{\mathrm{f}}$ values for Tzl-OH@Clin and IL-Tzl-OH@Clin as adsorbents were much greater than raw clinochlore, which results from the interactions between metal ions and ligands. Investigation of the correlation coefficient $\left(R^{2}\right)$ values indicated that the minimum value for $R^{2}$ in Langmuir model was 0.9972 and the maximum value was 0.9998 , all of which are very close to 1 . In Freundlich model, these values are 0.8883 and 0.9620 , respectively. By comparing $R^{2}$ values for Langmuir and Freundlich model, it can be concluded that the $R^{2}$ values for Langmuir model are closer to 1 than those for Freundlich model. It means the adsorption model of adsorbents is more corresponding to Langmuir model than to Freundlich model.

Also, the kinetic study of the adsorption process was carried out by using pseudo-first-order model and pseudosecond-order model (Eqs. 5 and 6).

$\ln \left(q_{\mathrm{e}}-q_{t}\right)=\ln q_{\mathrm{e}}-K_{1} t$

$\frac{t}{q_{t}}=\frac{1}{K_{2} q_{\mathrm{e}}^{2}}+\frac{t}{q_{\mathrm{e}}}$

where $q_{\mathrm{e}}(\mathrm{mg} / \mathrm{g})$ and $q_{t}(\mathrm{mg} / \mathrm{g})$ are the adsorption capacity at equilibrium and adsorption capacity at time $(t)$, respectively. In addition, $K_{1}(1 / \mathrm{min})$ and $K_{2}(\mathrm{~g} / \mathrm{mg} \mathrm{min})$ are the pseudofirst-order and pseudo-second-order constants, respectively.

The two kinetic models were fitted (Fig. 8) and the kinetic parameters calculated (Table 2).

According to the results, the $R^{2}$ values for the pseudofirst-order ranged from 0.9753 to 0.9938 and for pseudosecond-order it ranged from 0.9994 to 0.9998 . The $R^{2}$ values of pseudo-second-order model closer to 1 than those of pseudo-first-order model, which declares that the adsorption of metal ions by adsorbents is mostly performed through chemical adsorption (Ho and McKay 1998).

The adsorption capacities at different time intervals were also studied (Fig. 9). The results showed a sharp increase in the initial $25 \mathrm{~min}$. After $25 \mathrm{~min}$, the adsorption capacity did not change significantly.
Table 1 Langmuir and Freundlich isotherm parameters for adsorption of $\mathrm{Co}(\mathrm{II}), \mathrm{Pb}$ (II) and $\mathrm{Zn}$ (II) by raw clinochlore, Tzl-OH@Clin and IL-Tzl-OH@ Clin

\begin{tabular}{|c|c|c|c|c|c|c|c|}
\hline \multirow[t]{2}{*}{ Metal ion } & \multirow[t]{2}{*}{ Adsorbent } & \multicolumn{3}{|c|}{ Langmuir parameters } & \multicolumn{3}{|c|}{ Freundlich parameters } \\
\hline & & $q_{\max }(\mathrm{mg} / \mathrm{g})$ & $K_{\mathrm{L}}$ & $R^{2}$ & $n$ & $K_{\mathrm{f}}$ & $R^{2}$ \\
\hline \multirow[t]{3}{*}{$\mathrm{Co}(\mathrm{II})$} & Raw clinochlore & 28.73 & 0.0935 & 0.9986 & 2.82 & 6.043 & 0.9085 \\
\hline & Tzl-OH@Clin & 84.74 & 0.1873 & 0.9972 & 3.50 & 26.25 & 0.9355 \\
\hline & IL-Tzl-OH@Clin & 65.78 & 0.2880 & 0.9996 & 4.31 & 26.13 & 0.9293 \\
\hline \multirow[t]{3}{*}{$\mathrm{Pb}(\mathrm{II})$} & Raw clinochlore & 41.32 & 0.0641 & 0.9998 & 2.39 & 6.188 & 0.9620 \\
\hline & Tzl-OH@Clin & 90.09 & 0.2351 & 0.9979 & 3.53 & 29.55 & 0.8883 \\
\hline & IL-Tzl-OH@Clin & 76.92 & 0.3030 & 0.9998 & 4.00 & 29.14 & 0.9092 \\
\hline \multirow[t]{3}{*}{$\mathrm{Zn}(\mathrm{II})$} & Raw clinochlore & 30.58 & 0.1030 & 0.9993 & 3.18 & 7.514 & 0.9533 \\
\hline & Tzl-OH@Clin & 62.50 & 0.2689 & 0.9998 & 4.17 & 23.96 & 0.8892 \\
\hline & IL-Tzl-OH@Clin & 53.19 & 0.3715 & 0.9997 & 5.42 & 25.38 & 0.9278 \\
\hline
\end{tabular}



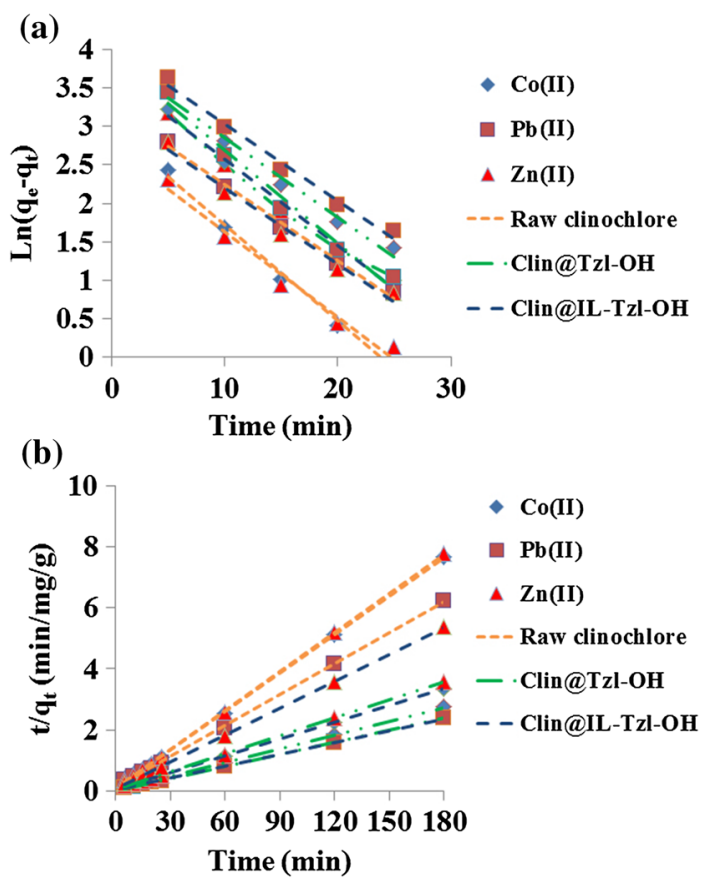

Fig. 8 Two kinetic models a pseudo-first order and $\mathbf{b}$ pseudo-second order of adsorption of $\mathrm{Co}$ (II), $\mathrm{Pb}$ (II) and $\mathrm{Zn}$ (II) by raw clinochlore, Tzl-OH@Clin and IL-Tzl-OH@Clin

The application of the adsorbents was also studied in the adsorption of heavy metal ions contained in wastewaters. In this regard, the specific amount of Tzl-OH@Clin (10,50 and $100 \mathrm{mg}$ ) was treated with the wastewater $(20 \mathrm{~mL})$ and stirred for $3 \mathrm{~h}$ in order to reach the equilibrium adsorption capacity at the room temperature. In the next step, the adsorbent was separated by centrifugation and the AAS of the remaining supernatant showed that the heavy metal ions were mostly removed after treated with adsorbent. The results are presented in Table 3.

In the case of using $10 \mathrm{mg}$ of Tzl-OH@Clin for adsorption of $\mathrm{Co}(\mathrm{II}), \mathrm{Pb}(\mathrm{II})$, and $\mathrm{Zn}(\mathrm{II})$, removal efficacy of $91 \%$, $89.50 \%$, and $90.25 \%$ was obtained, respectively. When the adsorbent amount was increased to $50 \mathrm{mg}$, these values were changed to $95 \%, 95.15 \%$ and $95.75 \%$. By increasing adsorbent amount to $100 \mathrm{mg}$, almost all the metal ions were adsorbed $(99.40 \%, 98.50 \%$ and $98.90 \%$ for $\mathrm{Co}(\mathrm{II}), \mathrm{Pb}(\mathrm{II})$ and $\mathrm{Zn}(\mathrm{II})$, respectively).

To find out the relationship between temperature and adsorption ability, we carried out the adsorption process at $25^{\circ} \mathrm{C}, 35^{\circ} \mathrm{C}$ and $45^{\circ} \mathrm{C}$ (Fig. 10).

In this regard, thermodynamic parameters such as standard enthalpy $\left(\Delta H^{\circ}\right)$, standard entropy $\left(\Delta S^{\circ}\right)$ and Gibbs free energy $\left(\Delta G^{\circ}\right)$ were calculated (Table 4$)$. The aforementioned parameters were calculated by Eqs. 7 and 8 as follows:

$K_{\mathrm{d}}=\frac{q_{\mathrm{e}}}{C_{\mathrm{e}}}$

$\ln K_{\mathrm{d}}=\frac{\Delta S^{\circ}}{R}-\frac{\Delta H^{\circ}}{R T}$

where $R(8.314 \mathrm{~J} / \mathrm{mol} \mathrm{K})$ is the universal gas constant, $T$ $\left({ }^{\circ} \mathrm{K}\right)$ is the solution temperature, and $K_{\mathrm{d}}$ is the distribution coefficient.

To calculate the free Gibbs energy $\left(\Delta G^{\circ}\right)$, Eq. 9 was used:

$\Delta G^{\circ}=-R T \ln K_{\mathrm{d}}$

The results of these calculations are inserted in Table 4. According to the results, $\Delta H^{\circ}$ and $\Delta S^{\circ}$ values are both positive, which means the adsorption processes are likely to be endothermic and carried out by entropy, respectively (Boparai et al. 2011). Furthermore, results of free Gibbs energy calculations showed that the values are all negative, which showed that the adsorption is a spontaneous process and the degree of spontaneity increased with raising temperature (Table 4).

In order to indicate the presence of metal ions in the adsorbent structure, XPS analysis was taken from TzlOH@Clin treated with standard metal ion solutions. Results showed two peaks at the binding energy of 780.68 and $796.58 \mathrm{eV}$, which are related to $\mathrm{Co}$ (II) $2 p_{3 / 2}$ and $\mathrm{Co}$ (II) $2 p_{1 / 2}$, respectively. Also, two deconvoluted peaks at 785 and
Table 2 Kinetic parameters of raw clinochlore, Tzl-OH@ Clin, and IL-Tzl-OH@Clin for adsorption of $\mathrm{Co}(\mathrm{II}), \mathrm{Pb}(\mathrm{II})$ and $\mathrm{Zn}(\mathrm{II})$

\begin{tabular}{|c|c|c|c|c|c|c|c|}
\hline \multirow[t]{2}{*}{ Metal ion } & \multirow[t]{2}{*}{ Adsorbent } & \multicolumn{3}{|c|}{ Pseudo-first-order } & \multicolumn{3}{|c|}{ Pseudo-second-order } \\
\hline & & $q_{\mathrm{e}}(\mathrm{mg} / \mathrm{g})$ & $K_{1}(1 / \mathrm{min})$ & $R^{2}$ & $q_{\mathrm{e}}(\mathrm{mg} / \mathrm{g})$ & $K_{2}(\mathrm{~g} / \mathrm{mg} \min )$ & $R^{2}$ \\
\hline \multirow[t]{3}{*}{$\mathrm{Co}(\mathrm{II})$} & Raw clinochlore & 19.47 & 0.1244 & 0.9915 & 23.81 & 0.02002 & 0.9996 \\
\hline & Tzl-OH@Clin & 48.43 & 0.1027 & 0.9865 & 66.67 & 0.00690 & 0.9997 \\
\hline & IL-Tzl-OH@Clin & 40.08 & 0.1115 & 0.9897 & 54.34 & 0.00887 & 0.9997 \\
\hline \multirow[t]{3}{*}{$\mathrm{Pb}(\mathrm{II})$} & Raw clinochlore & 25.16 & 0.0983 & 0.9938 & 29.59 & 0.01066 & 0.9994 \\
\hline & Tzl-OH@Clin & 49.31 & 0.1207 & 0.9766 & 75.75 & 0.00898 & 0.9998 \\
\hline & IL-Tzl-OH@Clin & 56.17 & 0.0997 & 0.9854 & 76.92 & 0.00582 & 0.9997 \\
\hline \multirow[t]{3}{*}{$\mathrm{Zn}(\mathrm{II})$} & Raw clinochlore & 15.33 & 0.1101 & 0.9753 & 23.41 & 0.02637 & 0.9998 \\
\hline & Tzl-OH@Clin & 37.20 & 0.1071 & 0.9873 & 51.02 & 0.00937 & 0.9997 \\
\hline & IL-Tzl-OH@Clin & 24.04 & 0.0982 & 0.9819 & 33.89 & 0.01407 & 0.9997 \\
\hline
\end{tabular}




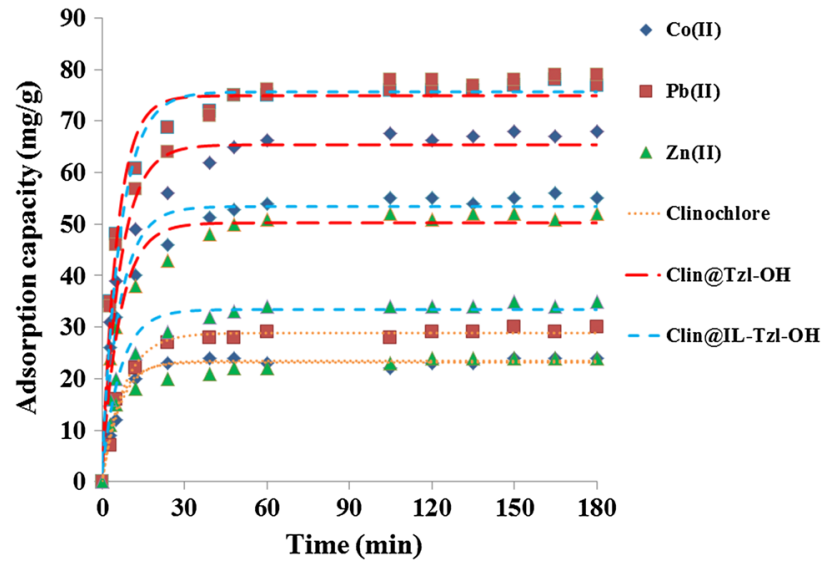

Fig. 9 Effect of time on equilibrium adsorption capacity for adsorption of $\mathrm{Co}(\mathrm{II}), \mathrm{Pb}(\mathrm{II})$ and $\mathrm{Zn}(\mathrm{II})$ by raw clinochlore, Tzl-OH@Clin and IL-Tzl-OH@Clin

Table 3 Removal efficacy of Tzl-OH@Clin treated with wastewater containing $\mathrm{Co}(\mathrm{II}), \mathrm{Pb}(\mathrm{II})$ and $\mathrm{Zn}$ (II)

\begin{tabular}{lcrlll}
\hline Metal ion & Adsorbent & $C_{A}^{\mathrm{a}}(\mathrm{mg})$ & $C_{0}^{\mathrm{b}}(\mathrm{mg} / \mathrm{L})$ & $C_{\mathrm{e}}^{\mathrm{c}}(\mathrm{mg} / \mathrm{L})$ & $\begin{array}{l}\text { Removal } \\
\text { efficacy } \\
(\%)^{\mathrm{d}}\end{array}$ \\
\hline Co(II) & Tzl-OH@ & 10 & 20 & 1.80 & 91 \\
& Clin & 50 & 20 & 0.75 & 95 \\
& & 100 & 20 & 0.12 & 99.40 \\
$\mathrm{~Pb}(\mathrm{II})$ & Tzl-OH@ & 10 & 20 & 2.10 & 89.50 \\
& Clin & 50 & 20 & 0.97 & 95.15 \\
& & 100 & 20 & 0.30 & 98.50 \\
$\mathrm{Zn}(\mathrm{II})$ & Tzl-OH@ & 10 & 20 & 1.95 & 90.25 \\
& Clin & 50 & 20 & 0.85 & 95.75 \\
& & 100 & 20 & 0.22 & 98.90 \\
\hline
\end{tabular}

aAmount of Tzl-OH@Clin

${ }^{\mathrm{b}}$ Initial concentration of heavy metal ion in wastewater

${ }^{c}$ Equilibrium concentration of heavy metal ion in wastewater

${ }^{\mathrm{d}}$ Removal efficacy was calculated by the equation: removal efficacy $(\%)=\left(\left(C_{0}-C_{\mathrm{e}}\right) / C_{0}\right) \times 100$

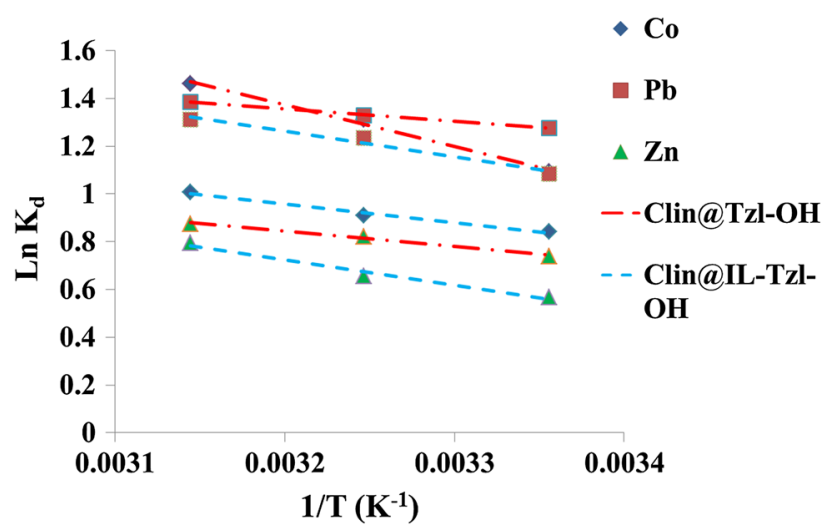

Fig. 10 Effect of temperature change on distribution coefficient $\left(K_{\mathrm{d}}\right)$
$800 \mathrm{eV}$ are related to $\mathrm{Co}(\mathrm{III})$ (Fig. 11a) (Patil et al. 2014). The study of XPS spectra in the $\mathrm{Pb}$ region revealed that two peaks at binding energy of 138 and $142.88 \mathrm{eV}$ are related to $\mathrm{Pb}$ (II) $4 f_{7 / 2}$ and $\mathrm{Pb}$ (II) $4 f_{5 / 2}$. Moreover, two peaks at 139.48 and $144.38 \mathrm{eV}$ are related to $\mathrm{Pb}(\mathrm{II})$ ions of $\mathrm{PbO}$ species (Fig. 11b) (Burungale et al. 2016). In the $\mathrm{Zn}$ region, two peaks at 1021.98 and $1045.08 \mathrm{eV}$ are related to $\mathrm{Zn}$ (II) species (Fig. 11c) (Xu et al. 2013).

The SEM-map and EDX analysis of Tzl-OH@Clin treated with metal ion solutions proved the presence of metal ions species in the adsorbents structures (Figs. 12 and 13).

Comparison of this work with some other relevant literatures showed that the prepared adsorbents exhibit appropriate adsorption capacities, and in some cases it is superior to some other related works. In addition, Tzl-OH@Clin could adsorb three kinds of heavy metal ions with an acceptable adsorption capacity values and also being as an eco-friendly adsorbent would make this clay-based adsorbent to be as a useful material on industries specifically in the way of declining pollutions (Table 5). Moreover, to broad our perspective in the applications of the prepared adsorbents, we investigated the catalytic ability of the aforementioned adsorbents.

In order to find out the catalytic activity of the adsorbents, the specific amount of them (15 $\mathrm{mg}$ ) was treated with heavy metal ion solutions. After $3 \mathrm{~h}$ (equilibrium time), the adsorbents were separated and washed by deionized water and acetone. Then, the concentrations of the metals adsorbed in the structure adsorbents were determined by AAS. Next, reduction of 1-chloro-4-nitrobenzene was selected as a model reaction to study the catalytic activity of the adsorbents with metals in their structures. In the beginning, the reactions were undergone with $15 \mathrm{mg}$ of three adsorbents containing metals ions as the catalyst (0.5-1.6 mol\% of metal in its structure) in deionized water as the solvent, sodium borohydride as the reducing agent and at room temperature. The highest yield was obtained using Tzl-OH@ Clin treated with $\mathrm{Co}(\mathrm{II})$ as the catalyst (Table 6).

In order to reach the optimized condition for the reduction of nitroarenes by Tzl-OH@Clin, we studied the reduction of 1-chloro-4-nitrobenzene at different temperatures (Table 7). Results indicated that $63 \%$ and $75 \%$ of the corresponding product were achieved when the temperatures were 25 and $35{ }^{\circ} \mathrm{C}$, respectively (entries 1 and 2, Table 7). Moreover, very good and excellent yields were obtained in the cases of 50 and $70{ }^{\circ} \mathrm{C}$ (entries 3 and 4, Table 7). However, as the amines are such sensitive agents to oxidization, so the high temperature like $70{ }^{\circ} \mathrm{C}$ could make amines to be oxidized by the oxygen contained in the atmosphere. In this regard, we chose $50{ }^{\circ} \mathrm{C}$ as the optimum temperature and tried to investigate the solvent effect in the reduction efficiency. In the next study, we determined the effect of different solvents in the reduction progression. Results showed the corresponding 
Table 4 Calculations of thermodynamic parameters of Tzl-OH@Clin and IL-Tzl-OH@ Clin

\begin{tabular}{|c|c|c|c|c|c|c|c|}
\hline \multirow[t]{2}{*}{ Adsorbent } & \multirow[t]{2}{*}{ Metal ion } & \multirow[t]{2}{*}{$T\left({ }^{\circ} \mathrm{C}\right)$} & \multirow[t]{2}{*}{$\Delta H(\mathrm{~kJ} / \mathrm{mol})$} & \multirow[t]{2}{*}{$\Delta S(\mathrm{~J} / \mathrm{mol} \mathrm{K})$} & \multicolumn{3}{|c|}{$\Delta G(\mathrm{~kJ} / \mathrm{mol})$} \\
\hline & & & & & $25^{\circ} \mathrm{C}$ & $35^{\circ} \mathrm{C}$ & $45^{\circ} \mathrm{C}$ \\
\hline \multirow[t]{3}{*}{ Tzl-OH@Clin } & $\mathrm{Pb}^{2+}$ & 25 & 4.33 & 25.15 & -3.19 & -3.29 & -3.40 \\
\hline & $\mathrm{Co}^{2+}$ & 25 & 14.52 & 57.87 & -2.50 & -2.59 & -2.67 \\
\hline & $\mathrm{Zn}^{2+}$ & 25 & 5.36 & 24.11 & -1.90 & -1.96 & -2.03 \\
\hline \multirow[t]{3}{*}{ IL-Tzl-OH@Clin } & $\mathrm{Pb}^{2+}$ & 25 & 8.98 & 39.24 & -2.72 & -2.81 & -2.90 \\
\hline & $\mathrm{Co}^{2+}$ & 25 & 6.42 & 28.52 & -2.50 & -2.20 & -2.27 \\
\hline & $\mathrm{Zn}^{2+}$ & 25 & 8.88 & 34.42 & -1.39 & -1.43 & -1.48 \\
\hline
\end{tabular}

and acetone to the aqueous medium. Results indicated that 95,92 and $90 \%$ of the product were obtained by the addition of THF, EtOH and acetone, respectively (entries 10-12, Table 8). Eventually, $15 \mathrm{mg}$ of the Tzl-OH@Clin treated with $\mathrm{Co}(\mathrm{II})$ [contains $1.60 \mathrm{~mol} \%$ of $\mathrm{Co}(\mathrm{II})$ ], $\mathrm{H}_{2} \mathrm{O} / \mathrm{THF}(9: 1)$ as the solvent and $\mathrm{NaBH}_{4}$ (4 equivalent) at $50{ }^{\circ} \mathrm{C}$ were selected as the optimization reaction condition.

By reaching the optimized reaction condition, reductions of other nitroarene derivatives were undergone (Table 9). The results indicated that nitronaphthalene was reduced to its corresponding amine harder than nitrobenzene due to its lower solubility (entries 1-2, Table 9). Also, 4-chloroaniline and 4-bromoaniline were achieved in excellent yields due to the existence of withdrawing groups on the para position of nitro group (entries 3-4, Table 9). Reduction of ortho and para nitro toluene achieved the corresponding products in excellent yields, but regarding the steric effect of ortho position, the ortho toluidine was gained in longer time and lower yield than para toluidine (entries 5-6, Table 9). Presence of the electron-donating groups such as methoxy $(-\mathrm{OMe})$ and hydroxy $(-\mathrm{OH})$ on the nitrobenzene ring could reduce the reaction rate and yields. In the case of 4-nitroanisole and nitrophenols isomers, corresponding products were obtained in excellent (94\%) and good yields (81-88\%), respectively (entries 7-10, Table 9). The catalyst effectively reduced the nitroarenes, and amine products were achieved in good-toexcellent yields (Table 9).

Furthermore, to investigate the reusability of Tzl-OH@ Clin, 1-chloro-4-nitrobenzene was selected as the model reaction. The catalyst was recycled for up to 4 cycles in the reduction. During the first 3 cycles, just a little change was observed ( $15 \%$ decline in the product yield). However, in the run 4 th, the yield was dropped to $57 \%$, which may be related to the leaching of the Co species into the reaction medium (Table 10). These results indicated that the catalyst could play a dominant role in the future industries by being as a sustainable and reusable adsorbent/catalyst type.

Next, we investigated the impact of additional THF, EtOH 


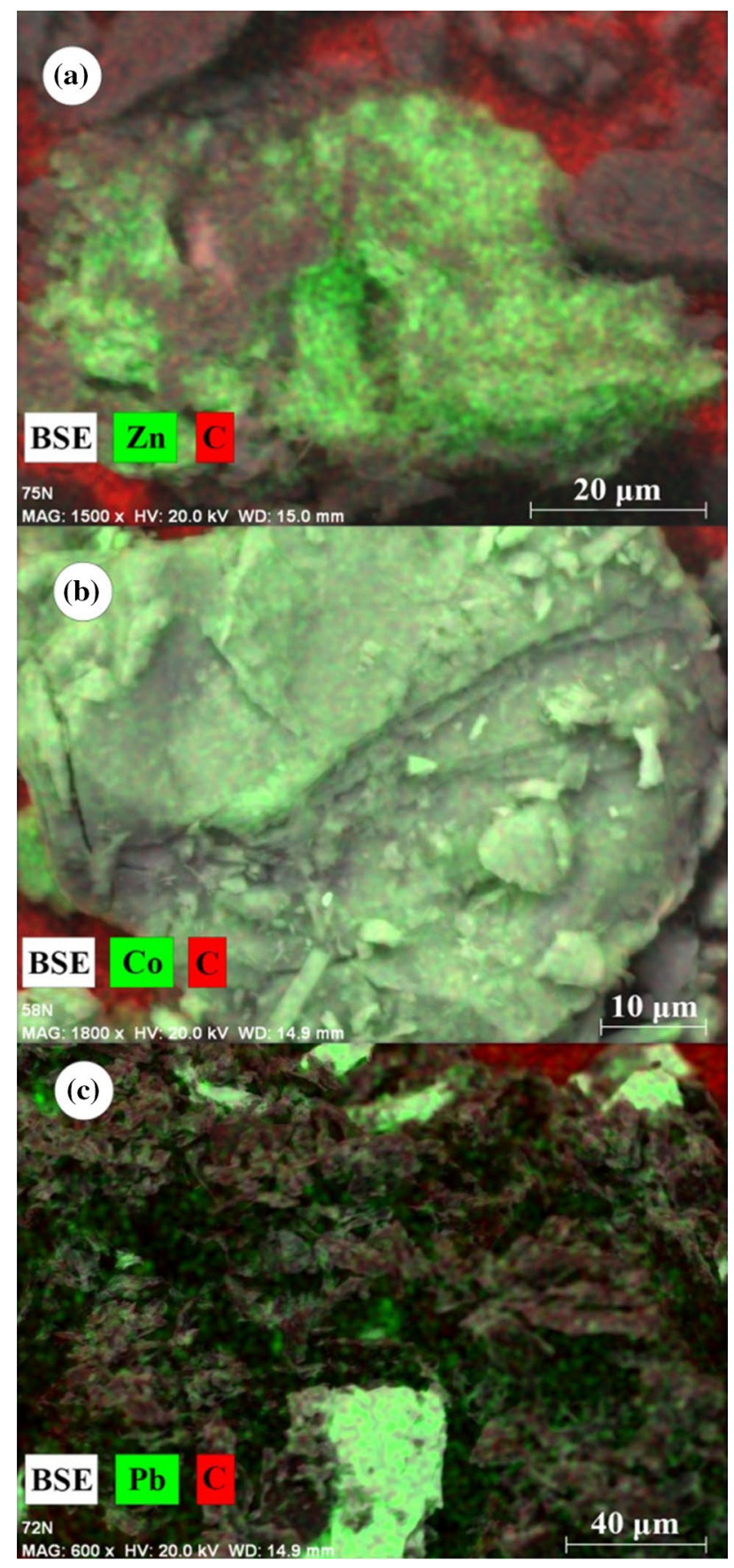

cps/eV

(a)
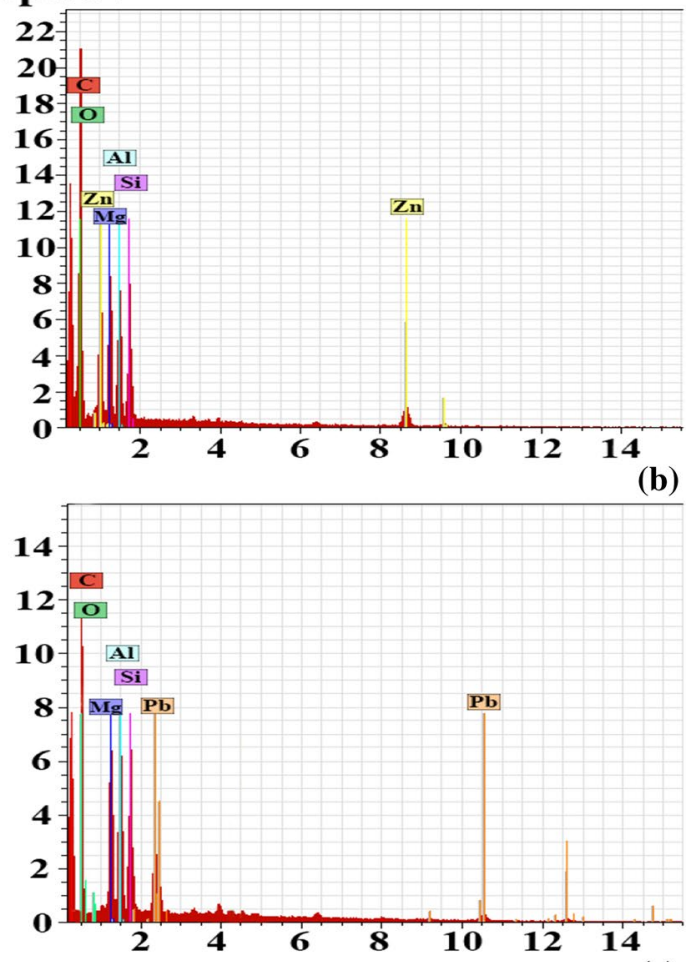

(c)

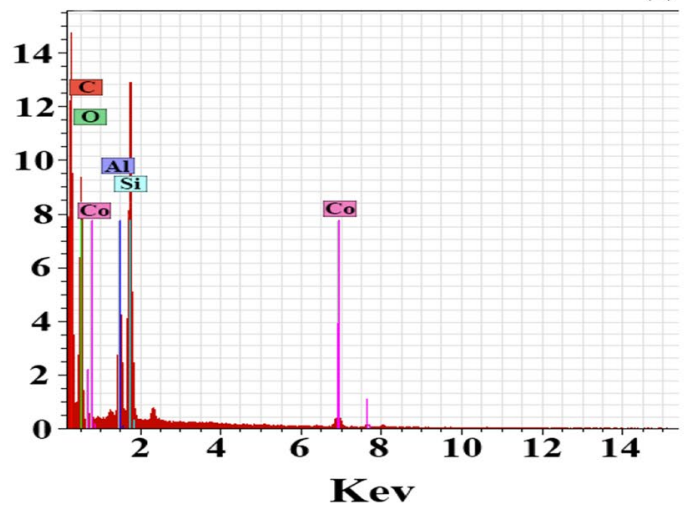

Fig. 13 EDX spectra of Tzl-OH@Clin treated with a $\mathrm{Zn}(\mathrm{II}), \mathbf{b} \mathrm{Pb}$ (II) and $\mathbf{c} \mathrm{Co}(\mathrm{II})$ solutions

Fig. 12 SEM-map images of Tzl-OH@Clin treated with a Zn(II), b $\mathrm{Co}$ (II) and $\mathbf{c} \mathrm{Pb}$ (II) standard solutions 
Table 5 Comparison of Tzl-OH@Clin with some other similar literatures based on the maximum adsorption capacity $\left(q_{\mathrm{m}}\right)$

\begin{tabular}{|c|c|c|c|c|}
\hline \multirow[t]{2}{*}{ Adsorbent } & \multicolumn{3}{|c|}{$q_{\max }(\mathrm{mg} / \mathrm{g})$} & \multirow[t]{2}{*}{ References } \\
\hline & $\mathrm{Co}^{2+}$ & $\mathrm{Pb}^{2+}$ & $\mathrm{Zn}^{2+}$ & \\
\hline Tzl-OH@Clin & 85 & 90 & 62 & This work \\
\hline Bent- $\mathrm{NH}_{2}$ & & 110 & & Anirudhan et al. (2012) \\
\hline MACCC & & 143 & & Le et al. (2018) \\
\hline FAU & 125 & & & Ltaief et al. (2015) \\
\hline $\mathrm{RC}$ & 21.1 & & 8.1 & Kumrić et al. (2013) \\
\hline MB15C5-B & & 47.5 & & $\begin{array}{l}\text { Bentouami and Ouali } \\
\text { (2006) }\end{array}$ \\
\hline MCB & & 58.88 & & Eren et al. (2009) \\
\hline HA-Am-PAA-B & 106.21 & & 52.93 & $\begin{array}{l}\text { Anirudhan and Suchithra } \\
\text { (2010) }\end{array}$ \\
\hline $\mathrm{Fe}_{3} \mathrm{O}_{4} /$ Bent-2.0 & & 81.5 & & Yan et al. (2016) \\
\hline
\end{tabular}

Table 6 Reduction of 1-chloro-4-nitrobenzene with adsorbents treated with metals as the catalysts

\begin{tabular}{|c|c|c|c|c|}
\hline \multicolumn{4}{|c|}{$\begin{array}{l}\text { Adsorbent treated with metal solution } \\
\qquad(15 \mathrm{mg})\end{array}$} & \\
\hline & \multicolumn{4}{|c|}{$\mathrm{H}_{2} \mathrm{O}$, r.t, $\mathrm{NaBH}_{4}$ (4 equiv) } \\
\hline Adsorbent & Metal ion & Mol\% & Time (h) & Yield $(\%)^{\mathrm{a}}$ \\
\hline \multirow[t]{3}{*}{ Raw clinochlore } & $\mathrm{Co}(\mathrm{II})$ & 0.50 & 12 & 21 \\
\hline & $\mathrm{Pb}(\mathrm{II})$ & 0.18 & 15 & 15 \\
\hline & $\mathrm{Zn}(\mathrm{II})$ & 0.50 & 13 & 20 \\
\hline \multirow[t]{3}{*}{ Tzl-OH@Clin } & $\mathrm{Co}(\mathrm{II})$ & 1.60 & 12 & $63^{\mathrm{b}}$ \\
\hline & $\mathrm{Pb}(\mathrm{II})$ & 0.54 & 15 & 34 \\
\hline & $\mathrm{Zn}(\mathrm{II})$ & 1.07 & 13 & 51 \\
\hline \multirow[t]{3}{*}{ IL-Tzl-OH@Clin } & $\mathrm{Co}(\mathrm{II})$ & 1.23 & 12 & 50 \\
\hline & $\mathrm{Pb}(\mathrm{II})$ & 0.52 & 15 & 31 \\
\hline & $\mathrm{Zn}(\mathrm{II})$ & 0.65 & 13 & 35 \\
\hline
\end{tabular}

Reaction condition: 1-chloro-4-nitrobenzene (1 mmol), $\mathrm{NaBH}_{4}$ (4 mmol), catalyst $\left(15 \mathrm{mg}\right.$ ) and $\mathrm{H}_{2} \mathrm{O}(1.5 \mathrm{~mL})$ at $25^{\circ} \mathrm{C}$

${ }^{\mathrm{a}} \mathrm{GC}$ yields

${ }^{\mathrm{b}}$ Optimum catalyst and reaction condions
Table 7 Optimization of temperature in the reduction of 1-chloro4-nitrobenzene<smiles>Nc1ccc(Cl)cc1</smiles>

\begin{tabular}{lll}
\hline Entry & $T\left({ }^{\circ} \mathrm{C}\right)$ & Yield $(\%)^{\mathrm{a}}$ \\
\hline 1 & 25 & 63 \\
2 & 35 & 75 \\
3 & 50 & 88 \\
4 & 70 & 95 \\
\hline
\end{tabular}

Reaction condition: 1-chloro-4-nitrobenzene (1 mmol), $\mathrm{NaBH}_{4}$ (4 mmol), catalyst $(15 \mathrm{mg})$, time $(12 \mathrm{~h})$ and $\mathrm{H}_{2} \mathrm{O}(1.5 \mathrm{~mL})$ at $25^{\circ} \mathrm{C}$

${ }^{\mathrm{a}} \mathrm{GC}$ yields

Table 8 Optimization of solvent in the reduction of 1-chloro-4-nitrobenzene

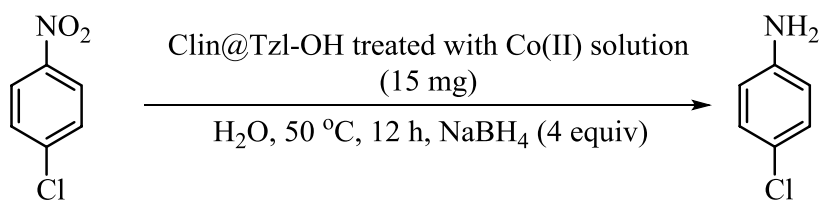

\begin{tabular}{llc}
\hline Entry & Solvent & ${\text { Yield }(\%)^{\mathrm{a}}}^{\mathrm{a}}$ \\
\hline 1 & $\mathrm{CH}_{3} \mathrm{CN}$ & 37 \\
2 & Ethyl acetate & 69 \\
3 & Acetone & 75 \\
4 & Toluene & 4 \\
5 & $\mathrm{CH}_{2} \mathrm{Cl}_{2}$ & 10 \\
6 & $\mathrm{CH}_{3} \mathrm{Cl}$ & 7 \\
7 & $\mathrm{THF}$ & 67 \\
8 & EtOH & 65 \\
9 & $\mathrm{H}_{2} \mathrm{O}$ & 88 \\
$\mathbf{1 0}$ & $\mathbf{H}_{\mathbf{2}} \mathrm{O} / \mathrm{THF}(\mathbf{9 : 1 )}$ & $\mathbf{9 5}$ \\
11 & $\mathrm{H}_{2} \mathrm{O} /$ EtOH $(1: 1)$ & 92 \\
12 & $\mathrm{H}_{2} \mathrm{O} /$ acetone $(4: 1)$ & 90 \\
\hline
\end{tabular}

Reaction condition: 1-chloro-4-nitrobenzene (1 mmol), $\mathrm{NaBH}_{4}$ $(4 \mathrm{mmol})$, catalyst $(15 \mathrm{mg})$, time $(12 \mathrm{~h})$ and solvent $(1.5 \mathrm{~mL})$ at $25^{\circ} \mathrm{C}$ ${ }^{\mathrm{a}} \mathrm{GC}$ yields

${ }^{\mathrm{b}}$ Optimized reaction conditions 
Table 9 Reduction of nitroarene derivatives with Tzl-OH@Clin treated with Co(II) as the catalyst

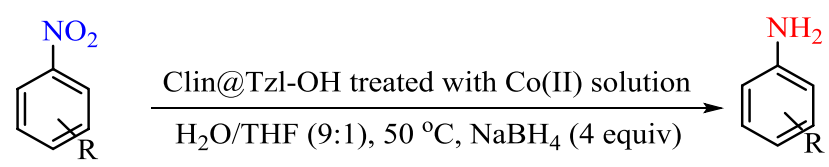

$\mathbf{6}$ ortho para $12 \mathrm{~h}, 93 \%$
$15 \mathrm{~h}, 90 \%$

Reaction condition: nitroarene ( $1 \mathrm{mmol}), \mathrm{NaBH}_{4}(4 \mathrm{mmol})$, catalyst $(15 \mathrm{mg})$ and $\mathrm{H}_{2} \mathrm{O} / \mathrm{THF}(1.5 \mathrm{~mL})$ at $50{ }^{\circ} \mathrm{C}$

GC yields

Table 10 Recycling of the Tzl-OH@Clin<smiles>O=[N+]([O-])c1ccc(Cl)cc1</smiles>

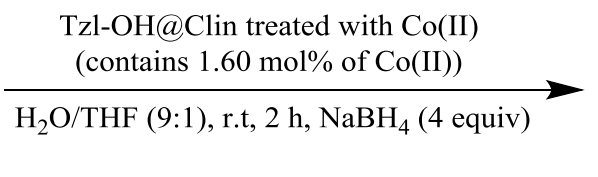<smiles>Nc1ccc(Cl)cc1</smiles>

\begin{tabular}{lllll}
\hline Number of cycles & 1 & 2 & 3 & 4 \\
\hline Yield of product $(\%)^{\mathrm{a}}$ & 95 & 87 & 80 & 57 \\
\hline
\end{tabular}

Reaction condition: 1-chloro-4-nitrobenzene $(0.5 \mathrm{mmol}), \mathrm{NaBH}_{4}$ ( $2 \mathrm{mmol})$, catalyst $(8 \mathrm{mg})$, time $(12 \mathrm{~h})$ and $\mathrm{H}_{2} \mathrm{O} / \mathrm{THF}(9: 1)(1.5 \mathrm{~mL})$ at $50^{\circ} \mathrm{C}$

${ }^{\mathrm{a}} \mathrm{GC}$ yields

\section{Conclusion}

The modification of the clinochlore was carried out by attachment of triazole and triazolium ligands to the clinochlore surface, and the new prepared materials (Tzl-OH@Clin and IL-Tzl-OH@Clin) showed excellent capability in the adsorption of toxic heavy metal ions such as $\mathrm{Co}(\mathrm{II}), \mathrm{Pb}(\mathrm{II})$ and $\mathrm{Zn}(\mathrm{II})$. Treated Tzl-OH@Clin with the solutions of heavy metal ions, particularly $\mathrm{Co}$, exhibited good catalytic activity in the reduction of nitroarenes. In the end, these materials indicated good adsorption efficacy in the heavy metal ion adsorption of industrial wastewaters and also could be as an effective catalyst after treated with heavy metal ion solutions.

Acknowledgements The authors are grateful to Jaber Ibn Hayyan Laboratory Foundation of NSTRI and Iran National Science Foundation (INSF-Grant No. 96001155) for supporting this research work. We are also grateful to Dr. Amir Hossien Ghorashi for his valuable comments and thoroughly editing the manuscript.

Open Access This article is distributed under the terms of the Creative Commons Attribution 4.0 International License (http://creativeco mmons.org/licenses/by/4.0/), which permits unrestricted use, distribution, and reproduction in any medium, provided you give appropriate credit to the original author(s) and the source, provide a link to the Creative Commons license, and indicate if changes were made.

\section{References}

Agudosi E, Salleh M, Abdullah E, Mujawar M, Khalid M, Azni A (2018a) Characterization of crystallized struvite on wastewater treatment equipment: prospects for crystal fertilizer production. Desalin Water Treat 113:205-212

Agudosi ES, Abdullah EC, Mubarak N, Khalid M, Pudza MY, Agudosi NP, Abutu ED (2018b) Pilot study of in-line continuous flocculation water treatment plant. J Environ Chem Eng 6(6):7185-7191

Altın O, Özbelge HÖ, Doğu T (1998) Use of general purpose adsorption isotherms for heavy metal-clay mineral interactions. J Colloid Interface Sci 198(1):130-140 
Alvarez-Ayuso E, Garćia-Sánchez A (2003) Removal of heavy metals from waste waters by natural and $\mathrm{Na}$-exchanged bentonites. Clays Clay Miner 51(5):475-480

Anirudhan T, Suchithra P (2010) Heavy metals uptake from aqueous solutions and industrial wastewaters by humic acid-immobilized polymer/bentonite composite: kinetics and equilibrium modeling. Chem Eng J 156(1):146-156

Anirudhan T, Jalajamony S, Sreekumari S (2012) Adsorption of heavy metal ions from aqueous solutions by amine and carboxylate functionalised bentonites. Appl Clay Sci 65:67-71

Bentouami A, Ouali M (2006) Cadmium removal from aqueous solutions by hydroxy- 8 quinoleine intercalated bentonite. J Colloid Interface Sci 293(2):270-277

Bessbousse H, Rhlalou T, Verchère J-F, Lebrun L (2008) Removal of heavy metal ions from aqueous solutions by filtration with a novel complexing membrane containing poly(ethyleneimine) in a poly(vinyl alcohol) matrix. J Membr Sci 307(2):249-259

Bhattacharyya KG, Gupta SS (2008) Adsorption of a few heavy metals on natural and modified kaolinite and montmorillonite: a review. Adv Colloid Interface Sci 140(2):114-131

Boparai HK, Joseph M, O'Carroll DM (2011) Kinetics and thermodynamics of cadmium ion removal by adsorption onto nano zerovalent iron particles. J Hazard Mater 186(1):458-465

Burungale VV, Devan RS, Pawar SA, Harale NS, Patil VL, Rao V, Ma Y-R, Eun J, Kim JH, Patil PS (2016) Chemically synthesized PbS nano particulate thin films for a rapid $\mathrm{NO}_{2}$ gas sensor. Mater Sci Pol 34(1):204-211

Celis R, Hermosin MC, Cornejo J (2000) Heavy metal adsorption by functionalized clays. Environ Sci Technol 34(21):4593-4599

Charerntanyarak L (1999) Heavy metals removal by chemical coagulation and precipitation. Water Sci Technol 39(10-11):135

Chenu C, Plante A (2006) Clay-sized organo-mineral complexes in a cultivation chronosequence: revisiting the concept of the 'primary organo-mineral complex'. Eur J Soil Sci 57(4):596-607

Dạbrowski A, Hubicki Z, Podkościelny P, Robens E (2004) Selective removal of the heavy metal ions from waters and industrial wastewaters by ion-exchange method. Chemosphere 56(2):91-106

de Sá A, Abreu AS, Moura I, Machado AV (2017) Polymeric materials for metal sorption from hydric resources. In: Water purification. Elsevier, pp 289-322

Eren E, Afsin B, Onal Y (2009) Removal of lead ions by acid activated and manganese oxide-coated bentonite. J Hazard Mater 161(2-3):677-685

Esalah J, Husein MM (2008) Removal of heavy metals from aqueous solutions by precipitation-filtration using novel organo-phosphorus ligands. Sep Sci Technol 43(13):3461-3475

Fortgang P, Tite T, Barnier V, Zehani N, Maddi C, Lagarde F, Loir A-S, Jaffrezic-Renault N, Donnet C, Garrelie F (2016) Robust electrografting on self-organized 3D graphene electrodes. ACS Appl Mater Interfaces 8(2):1424-1433

Fu F, Wang Q (2011) Removal of heavy metal ions from wastewaters: a review. J Environ Manag 92(3):407-418

Gopal N, Narasimhulu K, Rao JL (2004) Optical absorption, EPR, infrared and Raman spectral studies of clinochlore mineral. J Phys Chem Solids 65(11):1887-1893

Häni H (1990) The analysis of inorganic and organic pollutants in soil with special regard to their bioavailability. Int J Environ Anal Chem 39(2):197-208

Hemanthkumar GN, Parthasarathy G, Chakradhar RPS, Omkaram I, Rao JL, Ratnakaram YC (2009) Electron paramagnetic resonance studies on clinochlore from Longitudinal Valley area, northeastern Taiwan. Phys Chem Miner 36:447-453

Ho Y, McKay G (1998) A comparison of chemisorption kinetic models applied to pollutant removal on various sorbents. Process Saf Environ Prot 76(4):332-340
Jlassi K, Abidi R, Benna M, Chehimi MM, Kasak P, Krupa I (2018) Bentonite-decorated calix [4] arene: a new, promising hybrid material for heavy-metal removal. Appl Clay Sci 161:15-22

Kleppe AK, Jephcoat AP, Welch MD (2003) The effect of pressure upon hydrogen bonding in chlorite: a Raman spectroscopic study of clinochlore to $26.5 \mathrm{GPa}$. Am Miner 88(4):567-573

Kumrić KR, Đukić AB, Trtić-Petrović TM, Vukelić NS, Stojanović Z, Novaković JDG, Matović LL (2013) Simultaneous removal of divalent heavy metals from aqueous solutions using raw and mechanochemically treated interstratified montmorillonite/kaolinite clay. Ind Eng Chem Res 52(23):7930-7939

Le VT, Tran TKN, Tran DL, Le HS, Doan VD, Bui QD, Nguyen HT (2018) One-pot synthesis of a novel magnetic activated carbon/clay composite for removal of heavy metals from aqueous solution. J Dispers Sci Technol. https://doi.org/10.1080/01932 691.2018.1541414

Lin GHY (1987) Toxicity of nitroaromatic compounds. J Appl Toxicol $7(2): 151$

Lin S-H, Juang R-S (2002) Heavy metal removal from water by sorption using surfactant-modified montmorillonite. J Hazard Mater 92(3):315-326

Ltaief OO, Siffert S, Fourmentin S, Benzina M (2015) Synthesis of faujasite type zeolite from low grade Tunisian clay for the removal of heavy metals from aqueous waste by batch process: kinetic and equilibrium study. C R Chim 18(10):1123-1133

Ngah WW, Hanafiah M (2008) Removal of heavy metal ions from wastewater by chemically modified plant wastes as adsorbents: a review. Bioresour Technol 99(10):3935-3948

Nojiri N, Tanaka N, Sato K, Sakai Y (1980) Electrolytic ferrite formation system for heavy metal removal. J Water Pollut Control Fed 52:1898-1906

Obadia MM, Mudraboyina BP, Serghei A, Montarnal D, Drockenmuller E (2015) Reprocessing and recycling of highly cross-linked ion-conducting networks through transalkylation exchanges of C-N bonds. J Am Chem Soc 137(18):6078-6083

Padilla-Ortega E, Leyva-Ramos R, Flores-Cano J (2013) Binary adsorption of heavy metals from aqueous solution onto natural clays. Chem Eng J 225:535-546

Patil U, Lee SC, Sohn J, Kulkarni S, Gurav K, Kim J, Kim JH, Lee S, Jun SC (2014) Enhanced symmetric supercapacitive performance of $\mathrm{Co}(\mathrm{OH})_{2}$ nanorods decorated conducting porous graphene foam electrodes. Electrochim Acta 129:334-342

Riefler RG, Smets BF (2000) Enzymatic reduction of 2,4,6-trinitrotoluene and related nitroarenes: kinetics linked to one-electron redox potentials. Environ Sci Technol 34(18):3900-3906

Sabbioni G, Jones CR (2002) Biomonitoring of arylamines and nitroarenes. Biomarkers 7(5):347-421

Tokiwa H, Ohnishi Y, Rosenkranz HS (1986) Mutagenicity and carcinogenicity of nitroarenes and their sources in the environment. CRC Crit Rev Toxicol 17(1):23-58

Uddin MK (2017) A review on the adsorption of heavy metals by clay minerals, with special focus on the past decade. Chem Eng J 308:438-462

Velde B (1992) Introduction to clay minerals: chemistry, origins, uses and environmental significance. Chapman and Hall Ltd, London

Welch MD, Marshall WG (2001) High-pressure behavior of clinochlore. Am Miner 86(11-12):1380-1386

Xu D, Fan D, Shen W (2013) Catalyst-free direct vapor-phase growth of $\mathrm{Zn}_{1-x} \mathrm{Cu}_{x} \mathrm{O}$ micro-cross structures and their optical properties. Nanoscale Res Lett 8(1):46

Yan L, Li S, Yu H, Shan R, Du B, Liu T (2016) Facile solvothermal synthesis of $\mathrm{Fe}_{3} \mathrm{O}_{4}$ /bentonite for efficient removal of heavy metals from aqueous solution. Powder Technol 301:632-640

Yun CH, Prasad R, Guha AK, Sirkar KK (1993) Hollow fiber solvent extraction removal of toxic heavy metals from aqueous waste streams. Ind Eng Chem Res 32(6):1186-1195 
Zhu Y, Hu J, Wang J (2012) Competitive adsorption of Pb(II), Cu(II) and $\mathrm{Zn}$ (II) onto xanthate-modified magnetic chitosan. J Hazard Mater 221:155-161
Zwirner-Baier I, Neumann H-G (1999) Polycyclic nitroarenes (nitroPAHs) as biomarkers of exposure to diesel exhaust. Mutat Res Genet Toxicol Environ Mutagen 441(1):135-144 